\title{
Analysis of temporal and Spatial characteristics of Mangrove physiological structure parameters quantitative inversion based on time Series Sentinel-2 --Taking Shankou Mangrove Nature Reserve as an example
}

\author{
Shiwen Wang ${ }^{1}$, Hongchang $\mathrm{He}^{1}$, Bolin $\mathrm{Fu}^{1 *}$, Hongliang $\mathrm{Sun}^{1}$ \\ ${ }^{1}$ College of Geomatics and Geoinformation, Guilin University of Technology, No. 12 Jian'gan Road, Guilin, \\ Guangxi, China-1016224841@qq.com; hhe@glut.edu.cn; fbl2012@126.com; 1563432553@qq.com
}

KEY WORDS: Physiological Structural Parameters, Mangroves, Sequential Sentinel-2,Remote Sensing Inversion, Neural Network Algorithm

\begin{abstract}
:
The physiological structure parameter of vegetation is an important index to measure the ecological health status of mangroves, and it is of great value to measure the ecological health status. Taking Shankou Mangrove Nature Reserve of Guangxi as the study area, The Chlorophyll-A/B(CAB),Leaf Area Index (LAI),Fractional Vegetation Cover (FVC) and Fraction of absorbed photo synthetically active radiation (FAPAR) were calculated by using Sentinel-2 image data to calculate the chlorophyll content of mangrove vegetation in the study area. The BP neural network algorithm is used to verify the accuracy difference between the inversion results and the corresponding products of MODIS, and the dynamic changes of physiological structure parameters of vegetation in mangroves are further studied. Results showed that:(1)The correlation coefficients between LAI, CAB, FAPAR, FVC and MODIS products were higher than 0.71 in $95 \%$ confidence interval in mangrove years, it is proved that Sentinel-2A/B multispectral image inversion of mangrove physiological structure parameters has high accuracy and quality.(2)The physiological structure parameters of mangroves fluctuated during the year. In February, the lowest values of LAI,CAB,FAPAR and FVC were 0.30,0.08,0.08and 0.13, respectively. The highest values were 0.69 in October, 0.29 in December, 0.27 in August, 0.40 in April, 0.24 and 0.24 in September, and 0.27 and 0.33 in LAI in November, respectively, with the highest LAI in October, 0.29 in December, 0.27 in August, 0.40 in April, 0.24 and 0.24 in September, and 0.27 and 0.33 in November. The results provide the basis for the monitoring of mangrove vegetation change and provide a reference for ecological assessment and protection.
\end{abstract}

\section{INTRODUCTION}

Mangrove is one of the special wetland swamps, which grows in the coastal intertidal zone of tropics and subtropics. It has very unique ecological characteristics, at the same time, it plays an important role in preventing wave and protecting embankment, maintaining biodiversity and purifying the environment (Zhang Xuehong.2016),it plays an important role in ensuring coastal safety and biodiversity. In recent centuries, wetlands have been affected by varying degrees of impact, resulting in an accelerated rate of degradation, including sea level rise, unreasonable human development and climate change(Tian B et al,2015; Shao Y Y et al,2018).According to the survey, mangroves in China have decreased by more than
$50 \%$. Although the ecological situation of mangroves in some areas has improved, the protection and restoration of mangroves is urgent ( $\mathrm{Yu} \mathrm{L} \mathrm{Y} \mathrm{et} \mathrm{al,2019).The} \mathrm{physiological}$ structure parameter is one of the important parameters to evaluate the condition of the mangrove ecosystem, and The accurate acquisition of the parameter information of the physiological structure becomes the key to the study(Duan J H et al,2012).

At present, Some scholars have done a lot of research on the inversion of physiological structure parameters of wetland vegetation based on optical remote sensing images. The main methods to obtain physiological structure parameters are traditional empirical model method(Anatoly A et al,2002), vegetation index (Chen $\mathrm{P} P$ et al,2018) and spectral

Corresponding author: Bolin Fu (fb12012@126.com) 
decomposition (Mu Yachao,2017).. The BSTDEV, like Li Shan and others (Li Shanshan .Tian Qingjiiu,2013), has some advantages for estimating the leaf area index (LAI).Zaiming Zhou et al. (Zhou Z M et al,2018) use SPOT6 satellite and UAV data to estimate vegetation coverage (Fractional Vegetation Cover,FVC in Sansha Bay coastal wetland) and have high accuracy.Francisco Flores-de-Santiago et al. (John $M$ et al,2012) carried out ecological assessment of mangroves based on the determination of chlorophyll concentration (chlorophyll-A/B,CAB), LAI and leaf length).It was concluded that there was no significant seasonal difference in chlorophyll content in healthy mangroves.But the chlorophyll a content of the upper part of the canopy is high.Hu Bo et al. (Hu B et al,2013) have obtained the empirical equation of photosynthetic effective radiation suitable for Sanjiang region, and the relative error is relatively small.Xie Junhui et al.(Xie J F.Guo J,2016) analyzed the spatial distribution characteristics of photosynthetic active radiation absorption rate (Fraction of absorbed photosynthetically active radiation,FAPAR) of vegetation in Beijing in $2010-2012$ by using MODIS products. It was concluded that the spatial distribution of FAPAR was high in the east and west, and gradually decreased to the center.

In recent years, Some studies only discuss the change and growth trend of wetland vegetation from one or two physiological structural parameters from a certain spatial scale, it is ignored that the resolution of the image has a great difference in the accuracy of the physiological structure parameters of the time series. Therefore, based on Sentinel-2 image data, this study obtained the physiological structure parameters of mangroves in Shankou, Guangxi.Combined with MODIS image data, the data accuracy of Sentinel-2 image inversion physiological structure parameters is evaluated.;Four kinds of physiological structure parameters were used to analyze the growth and change of mangrove vegetation in the year, which provided the basis for monitoring the change of mangrove vegetation in Shankou, and provided a reference for ecological assessment and protection.

\section{STUDY AREA AND DATA SOURCE}

\subsection{Overview of the study area}

Shankou Mangrove $\left(21^{\circ} 29^{\circ} 00\right.$ " $21^{\circ} 33 \leq 25^{\prime \prime}$ N, $109^{\circ} 42$ ${ }^{\circ} 03$ " $109^{\circ} 45^{\circ} 36^{\prime \prime}$ E) National Nature Reserve is located on the east and west sides of Shatin Peninsula in Hepu County, Beihai City, Guangxi Zhuang Autonomous region, respectively, in the lower left corner of Danduhai Bay and the west side of Yingluo Bay,The east side of Yingluo Bay is the boundary of Guangdong Province (Li Shanshan .Tian Qingjiiu,2013), with a total area of 8000 hectares, as shown in figure 1.There are continuous or intermittent distribution of sea water in mangroves in Beibu Gulf, Guangxi, which has strong distribution characteristics and is obviously different from other ground objects,the plant resources of mangroves are abundant, and there are more than 370 species of vascular bundle plants (Fan H Q et al,2005),among them, there are very rare series of red sea elm pure forest and tall straight wood tree(Duan J H.Liang C L,2012) which have important scientific research value

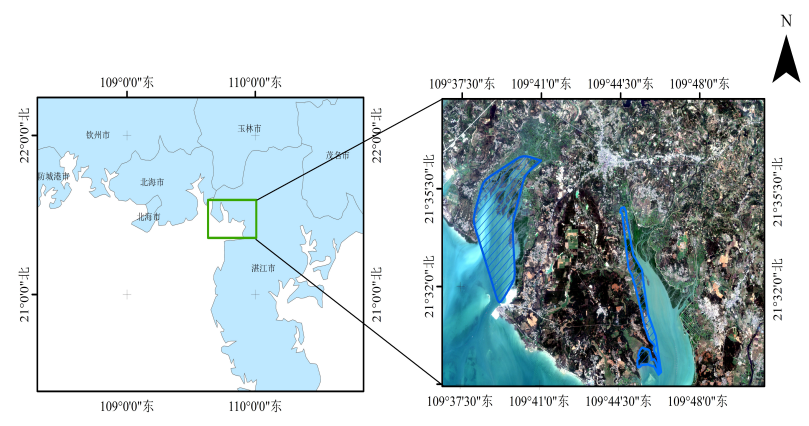

Figure 1. Shankou Mangrove Nature Reserve

\subsection{Data source acquisition and pre-processing}

The research data include Sentinel-2A/B image data, MODIS level 13, level 15 data product .Sentinel-2 (source: https://scihub.copernicus.eu/) belongs to the (ESA) satellite of the European Space Agency,these include two satellites, Sentinel-2A and Sentinel-2B, which complement each other, with a revisit cycle of five days and an altitude of $786 \mathrm{~km}$,it can cover 13 spectral bands with a width of $290 \mathrm{~km}$. The ground resolution is $10 \mathrm{~m}, 20 \mathrm{~m}$ and $60 \mathrm{~m}$, from visible and near-infrared to short-wave infrared, with different spatial resolutions. in optical data, sentinel-2 data is the only data with three bands in the red-edge range, which is very effective for monitoring vegetation health information.

MODIS Mid-resolution Imaging Spectrometer (Source:https://ladsweb.nascom.nasa.gov/data/search.html)., aboard Terra, Aqua two satellites, is an important sensor in the U.S. Earth Observation System of Systems (EOS) program.In this paper。 In this study, MODIS 13 (MOD13A2/ global $1 \mathrm{~km}$ resolution vegetation index 16 days synthesis) and 15 
(MOD15A2/ global 1km leaf area index / FAPAR 8 days synthesis) products were selected (Table 1).

Data preprocessing includes geometric resampling of Sentinel-2 images, geographical registration, radiometric calibration and terrain correction, Through the Sen2cor model provided by ESA (written in Python language), the number of bands is reduced to 10 after processing, which eliminates the influence of aerosol, water vapor and cirrus cloud band.MOD13 A2, MOD15 A2 products have completed geometric correction.

\begin{tabular}{|c|c|c|c|}
\hline $\begin{array}{c}\text { Imaging } \\
\text { time }\end{array}$ & $\begin{array}{c}\text { Spatial } \\
\text { resolution/ } \\
\text { m }\end{array}$ & Sensors & Levels \\
\hline \multirow{2}{*}{ 2019. 01} & 10 & Sentinel-2A/B & L2A \\
\hline & $500 / 1000$ & MODIS & 13、 15 \\
\hline \multirow{2}{*}{ 2018. 02} & 10 & Sentinel-2A/B & L2A \\
\hline & $500 / 1000$ & MODIS & 13、 15 \\
\hline \multirow{2}{*}{ 2018. 03} & 10 & Sentinel-2A/B & L2A \\
\hline & $500 / 1000$ & MODIS & 13、 15 \\
\hline \multirow{2}{*}{ 2018. 04} & 10 & Sentinel-2A/B & L2A \\
\hline & $500 / 1000$ & MODIS & 13、 15 \\
\hline \multirow{2}{*}{ 2018. 05} & 10 & Sentinel-2A/B & L2A \\
\hline & $500 / 1000$ & MODIS & 13、 15 \\
\hline \multirow{2}{*}{ 2016. 06} & 20 & Sentinel-2A/B & L2A \\
\hline & $500 / 1000$ & MODIS & 13、 15 \\
\hline \multirow{2}{*}{ 2017. 08} & 10 & Sentinel-2A/B & L2A \\
\hline & $500 / 1000$ & MODIS & 13、 15 \\
\hline \multirow{2}{*}{ 2018. 09} & 20 & Sentinel-2A/B & L2A \\
\hline & $500 / 1000$ & MODIS & 13、 15 \\
\hline \multirow{2}{*}{ 2018. 10} & 60 & Sentinel-2A/B & $\mathrm{L} 2 \mathrm{~A}$ \\
\hline & $500 / 1000$ & MODIS & 13、 15 \\
\hline \multirow{2}{*}{ 2018. 11} & 60 & Sentinel-2A/B & L2A \\
\hline & $500 / 1000$ & MODIS & 13、 15 \\
\hline \multirow{2}{*}{ 2017. 12} & 20 & Sentinel-2A/B & L2A \\
\hline & $500 / 1000$ & MODIS & 13、 15 \\
\hline
\end{tabular}

Table 1. Sentinel-2A/B multispectral imaging and MODIS data products

\section{RESEARCH METHODS}

3.1 Quantitative inversion of the remote sensing of the physiological structure of mangroves
The Sentinel-2 L2A image data is using the Biophysical Processor in the SNAP 5.0 software,the retrieval algorithm is based on a specific radiative transfer model related to strong assumptions,especially about the crown structure (turbid medium model).It mainly includes the generation of a comprehensive vegetation characteristics and related zenith (TOC) reflectivity database.The neural network is then trained to estimate the canopy characteristics from the TOC reflectance and the corresponding angle of the defined observation structure.For each biophysical variable, a specific neural network is calibrated.Each neural network consists of an input layer consisting of 11 standardized input data:B3、B4、B5、B6、 B7、B8a、B11、B12、cos(viewing_zenith)、cos(sun_zenith)、 cos(relative_azimuth_angle);5 neurons with transfer function in a hidden layer; an output layer with a linear transfer function.By this method, the show is carried out respectively LAI,CAB,FVC and FAPAR, Then call mosaicing and subset module to splice, cut and handle the biophysical indexes of six scenes, The physiological structure parameters of Shankou Mangrove Nature Reserve with spatial resolution of $10 \mathrm{~m}$ were obtained.Finally, LAI,CAB,FVC and FAPAR are imported into Arcgis10.2 software for analysis. The four structural parameters with resolution of $10 \mathrm{~m}$ are resampled to be consistent with the resolution of MODIS image data.

MODIS vegetation data products, in which 13-level products are directly capable of anti-show LAI and FAPAR through ArcGis10.2 software.And Class 15 MOD15A2 is made up of MODIS NDVI16 Day products, the calculated FVC formulae such as (1);NDVI was positively correlated with chlorophyll content,refit correlation analysis with NDVI.

$$
F V C=\frac{N D V I-N D V I_{\text {soil }}}{N D V I_{\text {veg }}-N D V I_{\text {soil }}}
$$

Where NDVIsoil is NDVImin;NDVIveg is NDVImax.Vegetation Index with NDVI as mixed Pixel;NDVIveg is the maximum of the pure vegetation image. The NDVIsoil is the minimum of the pure soil image.

\subsection{Construction of sentinel-2 inversion physiological} structure parameters and MODIS data Product regression

\section{Model based on BP Neural Network}

In this study, the BP neural network was used to realize the univariate linear regression and correlation analysis between the physiological parameters of the Sentinel-2A/B image data 
and the corresponding MODIS data products. The network shared 3-layer structure includes an input layer, an output layer, and an implicit layer.The obtained data from January to December are divided into 11 groups of data, each group of data is divided into test set and training set according to the proportion of 2:1, The data of the training set is input into the model for learning, and the data of the test set verifies the results of the building model output. By selecting the input layer, the output layer and the hidden node of the network, The training data are used to establish the verification model suitable for Shankou mangroves, and the test set is used to verify the constructed model to evaluate the accuracy of the verification model.The input layer is the monthly Sentinel-2A/B image data, The output layer is corresponding to the monthly MODIS data products, and the approximate relationship between the number of neurons in the Figure 2 . Regression model of interannual physiological structure parameters hidden layer $\mathrm{b}$ and the number of input neurons $\mathrm{a}$ is as follows (2):

$$
b=2 a+1
$$

Because the number of neurons in the input layer is 1 , the number of hidden layers is 3.A three-layer BP neural network model is constructed.After repeated training, the number of the hidden layer neurons is determined to be 3 , the number of the training set iterations is 10000 , the training goal of 0.0001 model is better than that of the model, and the model is shown in figure 2.According to Table 2, the annual average root mean square error (RMSE), correlation coefficient (R) and the determination coefficient (R2) accuracy evaluation index of the four physiological structure parameters can be seen,As a whole, the interannual average $\mathrm{R} 2>0.82, \mathrm{R}>0.89$, RMSE $>0.15$; From the regression model of physiological structural parameters (figure 2),The closer the sample point to the trend line indicates that the physiological structure parameter values of the Sentinel-2 inversion are closer to the MODIS data product values, there is a good correlation.

\begin{tabular}{|c|c|c|c|}
\hline Physiological structure parameters & $\mathrm{R}$ & $\mathrm{R}^{2}$ & RMSE \\
\hline LAI & 0.92 & 0.92 & 0.19 \\
CAB & 0.86 & 0.66 & 0.18 \\
FAPAR & 0.87 & 0.85 & 0.14 \\
FVC & 0.93 & 0.84 & 0.09 \\
\hline
\end{tabular}

Table2. Model coefficient of interannual physiological structure parameter
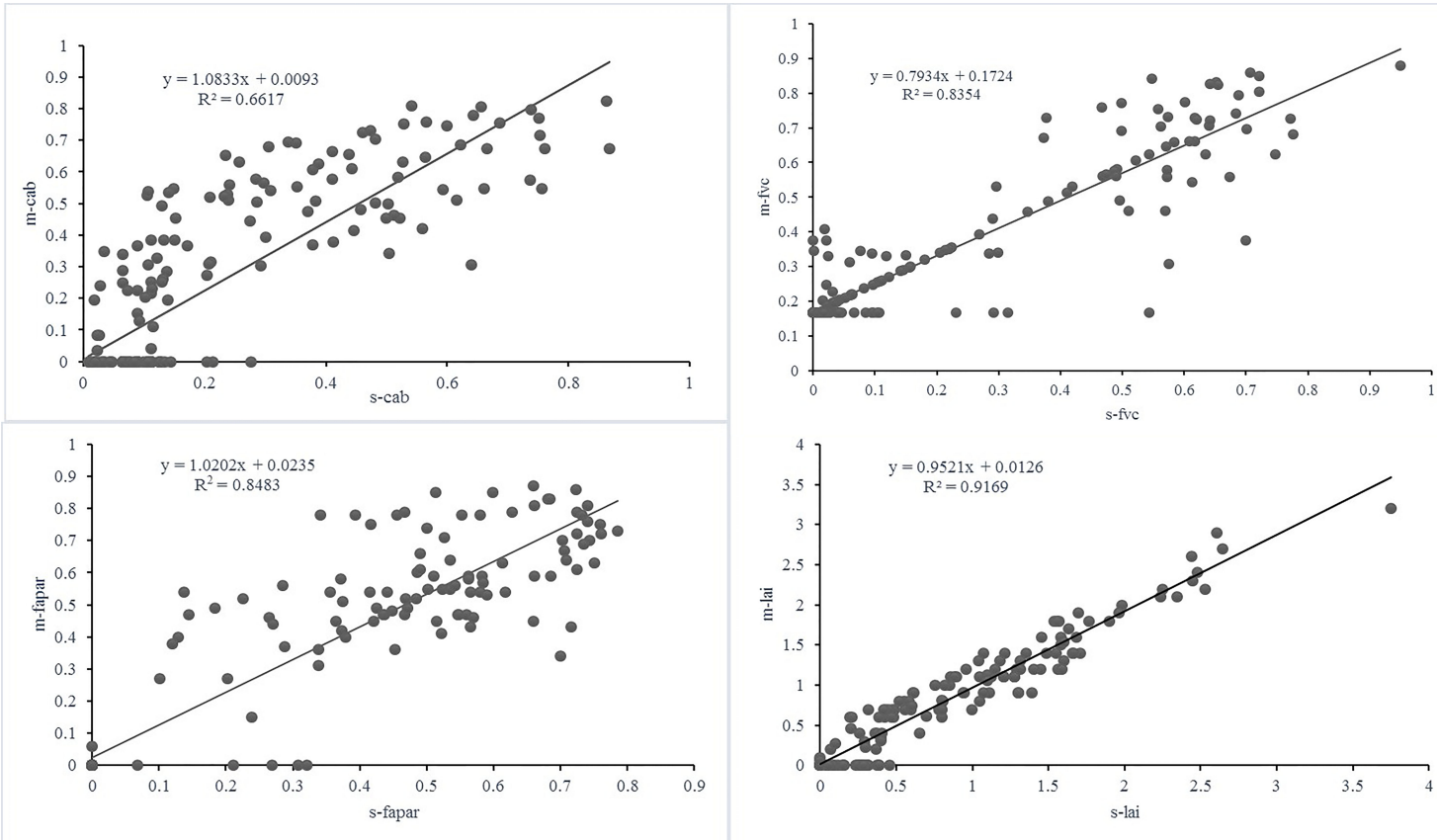

Figure 2. Regression model of interannual physiological structure parameters 


\section{RESULTS AND DISCUSSION}

\section{1 comparison and Verification of Sentinel-2A/B Image} data based on MODIS Image products

Based on BP neural network, the linear regression analysis of MODIS product image data and Sentinel-2A/B image data is carried out,the correlation coefficient $(\mathrm{R})$ was higher than 0.71 in $95 \%$ confidence interval,the effect is better.Fig. 3 shows the change of the precision index of the four physiological structure parameters of mangroves on a monthly basis,the overall view is relatively stable,the overall view is relatively stable, and the cause of the dip is closely related to nature and man-made, such as rising sea level, sudden changes in climate, and human-induced deforestation(Wu P Q et al,2018).The inversion effect of Sentinel-2A/B image data is better.

4.2 monthly changes in physiological structure parameters
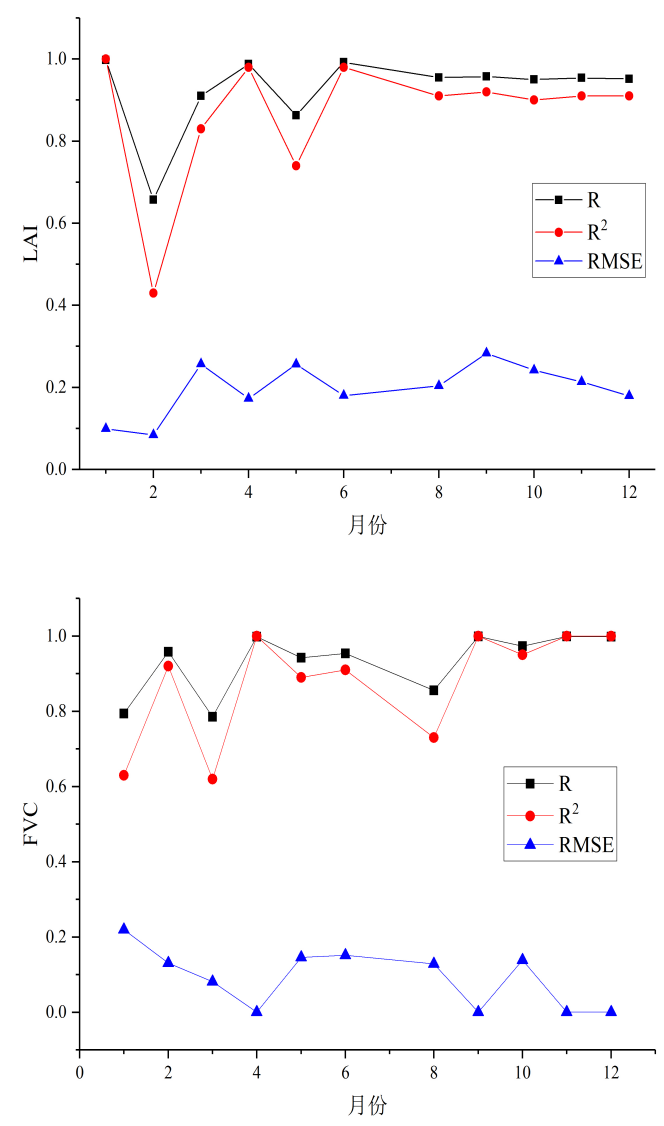

In this study, the average value of monthly Sentinel-2A/B image data after inversion (Table 3).As shown in figure 4. It can be seen that there is a tendency of the fluctuation of the physiological structure parameters in the mangroves, the lowest value is generally found in February,Because the vegetation is in the growth state from January to February, the parameter value is low; $\mathrm{CAB}$ showed the lowest values of 0.008 and 0.09 in February and May, which gradually increased from 0.19 in August to 0.89 in December, and stabilized to 0.27 in November.The lowest value of LAI began to rise to 0.60 in January, the highest value was 0.69 in October, and stabilized to 0.33 in November.FVC showed the highest value of 0.40 in April and the lowest value of 0.13 in February, until September and began to stabilize at 0.24 .FAPAR showed the lowest value of 0.08 in February, the highest value in September was 0.27 , and began to stabilize at 0.24 in October.
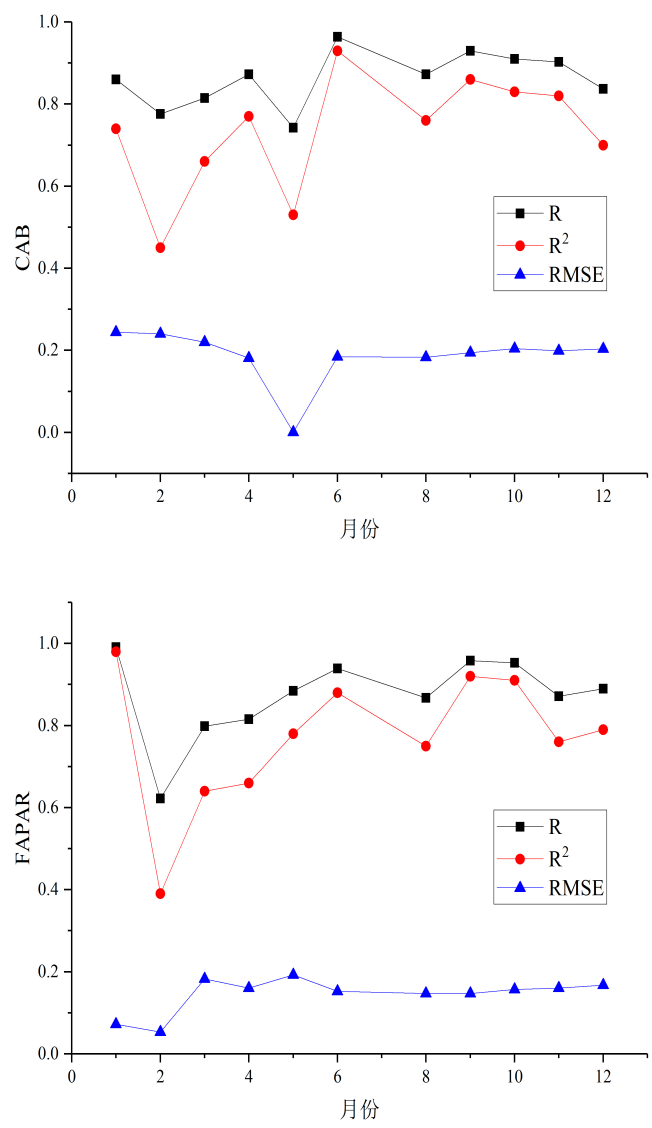

Figure 3. Variation of accuracy Indexes of four physiological structure parameters in Mangrove during the year 
The International Archives of the Photogrammetry, Remote Sensing and Spatial Information Sciences, Volume XLII-3/W10, 2020 International Conference on Geomatics in the Big Data Era (ICGBD), 15-17 November 2019, Guilin, Guangxi, China

\begin{tabular}{|c|c|c|c|c|}
\hline Months & CAB & FAPAR & FVC & LAI \\
\hline 01 & 0.21 & 0.20 & 0.18 & 0.17 \\
\hline 02 & 0.08 & 0.08 & 0.13 & 0.30 \\
\hline 03 & 0.28 & 0.22 & 0.21 & 0.43 \\
\hline 04 & 0.25 & 0.22 & 0.39 & 0.44 \\
\hline 05 & 0.09 & 0.21 & 0.19 & 0.59 \\
\hline 06 & 0.23 & 0.25 & 0.32 & 0.40 \\
\hline 08 & 0.19 & 0.19 & 0.28 & 0.36 \\
\hline 09 & 0.23 & 0.27 & 0.25 & 0.62 \\
\hline 10 & 0.23 & 0.26 & 0.26 & 0.68 \\
\hline 11 & 0.25 & 0.24 & 0.21 & 0.32 \\
\hline 12 & 0.29 & 0.24 & 0.21 & 0.34 \\
\hline
\end{tabular}

Table 3. Inversion of average vegetation structure parameters based on Sentinel-2A/B Image data from January to December
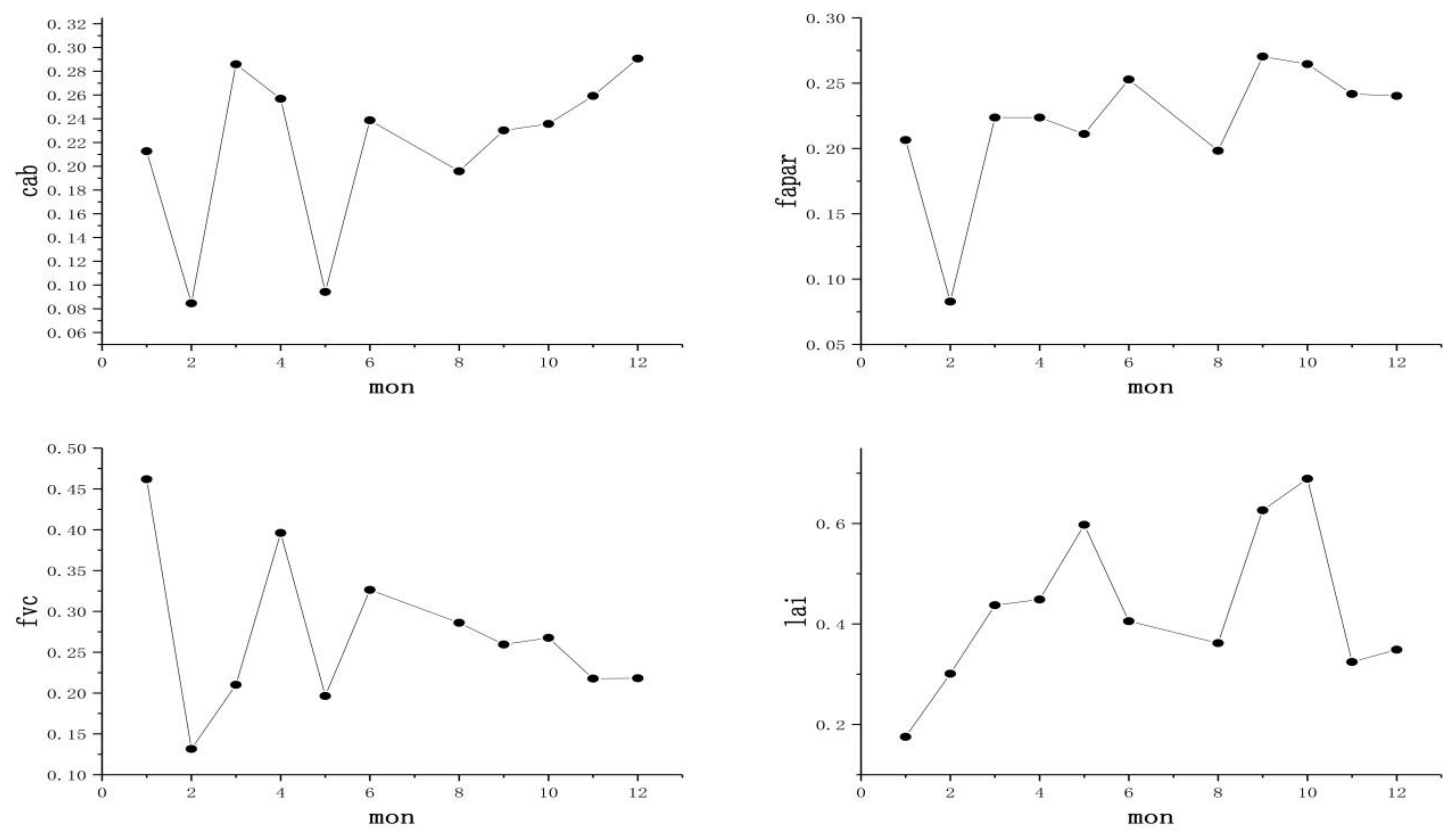

Figure 4. a line chart of the variation of four physiological structure parameters in the year 


\section{CONCLUSION}

This study is based on MODIS data products, using BP neural network model, based on Sentinel-2 image data inversion of four physiological structure parameters, including CAB,FVC,LAI and FAPAR, from time series and space, the dynamic change of vegetation in the mangroves of the mountain pass of Guangxi is grasped,The following conclusions are obtained for the inversion, comparison and analysis of four physiological structure parameters of mangroves:The four physiological structure parameters of the Sentinel-2 image data are basically the same as the trend of the MODIS data product,there is a good correlation, so using Sentinel-2A/B multispectral image to retrieve the physiological structure parameters of mangroves has high accuracy and quality; There is a trend of fluctuation in the physiological structure parameters of mangroves in Shankou during the year.In February, the lowest values of LAI,CAB,FAPAR and FVC were $0.30,0.08,0.08$ and 0.13 , respectively. The highest value is presented in October, December, August and April respectively. It is possible to reduce the index of sudden change or felling in a certain month, and further study it.The results provide the basis for the monitoring of mangrove vegetation change and provide a reference for ecological assessment and protection.

\section{ACKNOWLEDGMENT}

This study was funded by the National Natural Science Foundation of China (Grant No. 41801071), Natural Science Foundation of Guangxi (Grant No. 2018GXNSFBA281015), and Guilin university of technology scientific research Foundation (Grant No. GUTQDJJ2017096).

\section{REFERENCES}

Zhang, Xuhong.,2016:Automatic extraction of mangrove information from Landsat8 OLI image based on decision tree method. Land and resources remote sensing.28 (02):182-187. Tian, B., Zhou , Y, X., Thom, R, M., et al., 2015:Detecting wetland changes in shanghai,china using FORMOSATan Landsat TM imagery ,Journal of Hydrology.0529:1-10
Shao, Y, Y., Zhou, J, W., Mu, R, M., etc.,2018 Study on urban development and wetland protection in China. Journal of Ecological Environment, 18 (1): 47

Yu, L, Y., Lin J, H., Jiao, X, Y., Shen, X, X., Li, R, L.,2019: Ecological Problems and Countermeasures for Conservation of Mangrove Wetlands in Guangdong-Hong Kong-Macau Greater Bay Area. Journal of Peking University (Natural Science Edition), 55 (04): 782-790.

Wu, G, J., Guo Z, H., Guo J, L., Zhu Y, J.,2013: Progress in remote sensing estimation of aboveground biomass in mangrove wetlands . Journal of Southern Agriculture, 44 (04): 693.

Anatoly, A., Gitelson, Yoram, J, Kaufman, Robert Stark.,2002:Don Rundquist. Novel algorithms for remote estimation of vegetation fraction. Remote Sensing of Environment,80(1).

Chen, P, P., Shen, C, C., Wu, Z, L., Zheng, M, X., 2018:Study on the Time-varying Characteristics of NDVI in the Forest of the Multi-angle Remote Sensing Data. Southern agriculture,12 (19):15-18.

Mu, Y, C., 2017:Vegetation information extraction in northwest farming-pastoral ecotone based on Landsat image . Lanzhou University,

Li, S, S., Tian Q, J., 2013:LAI estimation based on characteristic index of mangrove trees of environmental stars . Remote Sensing Information, 28 (01): 16: 19.

Zhou, Z, M., Yang, Y, M., Chen, B, Q., 2018:Estimating Spartina alterniflora fractional vegetation cover and aboveground biomass in a coastal wetland using SPOT6 satellite and UAV data. Aquatic Botany,144.

Francisco, Flores-de-Santiago, John M., Kovacs, Francisco ,Flores-Verdugo.,2012: Seasonal changes in leaf chlorophyll a content and morphology in a sub-tropical mangrove forest of the Mexican Pacific. Marine Ecology Progress Series,.444:57-68.

Hu, Bo., Wang, Y,S., 2014: Observational Study of Variation of Photosynthetically Active Radiation in the Sanjiang Plain.Climatic and Environmental Research(inChinese),19(3):343-350,doi:10.3878/j.issn.1006-95 85.2013 .12181

Xie, J, F., Guo, J.,2016:temporal and spatial variation of photosynthetic active radiation absorption ratio of vegetation in Beijing from 2010 to 2012 . Journal of Applied Ecology, 27 (04): $1203-1210$ 
The International Archives of the Photogrammetry, Remote Sensing and Spatial Information Sciences, Volume XLII-3/W10, 2020 International Conference on Geomatics in the Big Data Era (ICGBD), 15-17 November 2019, Guilin, Guangxi, China

Fan, H, Q., Chen, G, H., He, B., etc. 2005: Coastal Wetland and Management of Mangrove in Shankou. Beijing: ocean Publishing House.

Duan, J, H., Liang, C, L., 2012:Study on the Countermeasures of Ecotourism Development of Mangrove Wetland in Beihai Shankou. Popular Technology, 14 (06): 319 -321.

Wu, P, Q., Zhang, J., Ma Y., Ren, G, B., 2018:Remote sensing monitoring and analysis of mangrove resource change in Thailand between 1980 and 2015. Marine Science Progress,36 (03):412-422. 